\title{
International Journal of
}

\section{Health Care and Biological Sciences}

Research Article

Open Access

\author{
Nanosuspension formulation \& evaluation of ritonavir \& valsartan by using \\ poloxamer as a stabilizing agent to enhance the oral bio availability \\ Sudhakar Kancharla ${ }^{1}$, Prachetha Kolli² , Dr.K.Venkata Gopaiah3*. \\ 1. Director Clinical Laboratory, Devansh Lab Werks,234 Aquarius Drive, Homewood, Alabama, USA-3520. \\ 2. Scientist, Microgen Health Inc, 14225, Sullyfield Cir Suite E, Chantilly, VA, USA-2015. \\ 3. Associate Professor St. Mary's College of Pharmacy, Chebrolu, Guntur-A.P-522 212-India
}

\begin{tabular}{|c|c|}
\hline Article History & Abstract \\
\hline Received on: 18-01-2021 & \multirow{5}{*}{$\begin{array}{l}\text { The Nano ionization technology is particularly promising for improving the } \\
\text { oral absorption and bioavailability of BCS class II drugs. One such approach is } \\
\text { Nano ionization thereby increasing surface area and hence dissolution and } \\
\text { ultimately the bioavailability. Ritonavir is a BCS class II and IV drug. Valsartan } \\
\text { is a commonly used antihypertensive agent belonging to the family of } \\
\text { angiotensin II receptor antagonists. Valsartan is a BCS class II drug being slightly } \\
\text { soluble in water. It has a very low oral bioavailability of 25-35\% due to its } \\
\text { limited solubility in biological fluids. Poor water solubility of drugs shows } \\
\text { insufficient bioavailability and fluctuating plasmalevels. Based on their } \\
\text { physicochemical and biopharmaceutical properties, Ritonavir and Valsartan } \\
\text { were selected as a drug candidates for developing Nanosuspension } \\
\text { based formulations for improving the solubility and bioavailability by } \\
\text { enhancing the rate and extent ofdissolution.The scope of the present work is to } \\
\text { enhance the solubility, dissolution rate and oral bio availability of poorly soluble } \\
\text { drugs Ritonavir and Valsartan by formulating them into Nanosuspension with } \\
\text { Poloxamer as a stabilizing agent and subsequently converting the optimized } \\
\text { Nanosuspension of Ritonavir/Valsartan drug molecule into tablets and } \\
\text { capsuleswith the help of various extragranular agents. }\end{array}$} \\
\hline Revised On : 16-02-2021 & \\
\hline Accepted on : 23-02-2021 & \\
\hline $\begin{array}{l}\text { Keywords: Valsartan, Ritonavir, } \\
\text { BCS. }\end{array}$ & \\
\hline $\begin{array}{l}\text { DOI: } \\
\text { https://doi.org/10.46795/ijhcbs.vi.137 }\end{array}$ & \\
\hline
\end{tabular}

(C) 2021 Puoduced by South Asian Academic Publications. This is an open access article under the CC BY license (https://creativecommons.org/licenses/by/4.0/

\section{*Corresponding Author}

Dr.K.Venkata Gopaiah.

Associate Professor

St. Mary's College of Pharmacy,

Chebrolu, Guntur-A.P-522 212-India

\section{Introduction}

An increased demand for more patient friendly dosage forms has been observed since from past few years. The oral route of drug administration is the most preferred method of delivery due to convenience and ease of ingestion. From a patient's perspective swallowing a dosage form is a comfortable and a familiar means of taking medication. Although oral route of administration is preferred for many drugs it can be a problematic and inefficient mode of delivery for a number of reasons. Limited drug absorption resulting in poor bioavailability is most common among the problems that can be encountered when delivering an active agent via oral route. Drug absorption from the gastro intestinal tract can be limited by various factors with the most common one being poor aqueous solubility and poor permeability of a drug molecule. When delivering an active ingredient orally, it must first dissolve in gastrointestinal fluids before it can permeate 
the membranes of the gastro intestinal tract to reach systemic circulation. Therefore, a drug with poor aqueous solubility will exhibit dissolution rate limited absorption. Solubility behavior of a drug plays a key role for its oral bioavailability. For some drugs solubility presents a challenge to the development of a suitable formulation for oraladministration. The solubility of any drug may be the critical factor determining its usefulness, since aqueous solubility dictates the amount of compound that will dissolve and therefore, the amount available for absorption. If a compound has a low aqueous solubility, it may be subject to dissolution rate-limited absorption within the gastrointestinal (GI) residence time. Drug absorption requires that molecules be in solution at the absorption site. Dissolution of solid dosage forms in gastrointestinal fluids is a prerequisite to the delivery of a drug to the systemic circulation following oral administration. Dissolution depends in part on the solubility of drug substance in the surroundingmedium.

Solubility characteristics play an important role in the initial process of drug dissolution to reach systemic circulation. Hydrophilicity favors drug dissolution in the aqueous medium, while lipophilicity favors subsequent penetration into the lipoidal membrane. For efficient absorption, aproper balance between these opposing propertiesis required. Hence solubility is one of thekey factors that governs the concentration of drug in the systemic circulation which is responsible for eliciting the desired therapeuticresponse.

Fairly soluble drugs in gastrointestinal (GI) media exhibit complete oral absorption, and thus good bioavailability. About $40 \%$ of drugs are not soluble in water in practice and therefore are slowly absorbed, which results in insufficient and uneven bioavailability and GI toxicity. Thus, most exigent phase of drug development practice particularly for oral dosage forms is the enhancement of drug solubility thereby its oral bioavailability. Bioavailability refers to the amount of therapeutically active drug that approaches the systemic circulation and thus, is available at the site of action. There are two reasons proposed for poor aqueous solubility of drugs,

\section{Highlipophilicity}

Strong inter molecular forces which cause insolubilization ofdrugs. Various approaches have been proposed to enhance solubility of poorly water soluble drugsfor the improvement of their bioavailability. The methodologies commonly used for drug solubilization includes micronization, chemical modification, $\mathrm{pH}$ adjustment, solid dispersion, complexation, co-solvency, micellar solubilizationand hydrotropy. There are numerous chemical molecules which experience low aqueous solubility problems. Although these molecules have prospective pharmacodynamics properties, they exhibit low bioavailability, which can be attributable to poor aqueous solubility and therefore, these molecules turn into abortive entities.

\section{Solubility}

Solubility is defined in quantitative terms as the concentration of solute in a saturated solution at a certain temperature and in a qualitative way, it can be defined as the spontaneous interaction of two or more substances to form a homogeneous molecular dispersion. Solubility is the amount of a substance that has passed into solution when equilibrium is attained between the solution and excess(i.e.,un-dissolved) substance at a given temperature and pressure. IUPAC defines solubility as the analytical composition of a saturated solution expressed as a proportion of a designated solute in a designated solvent. Solubility may be stated in units of concentration, molality, mole fraction, mole ratio and otherunits. Solubility is the property of a solid, liquid, or gaseous chemical substance called solute to dissolve in a solid, liquid, or gaseous solvent to form a homogeneous solution of the solute in the solvent. The solubility of a substance fundamentally depends on the solvent used, as well as on temperature and pressure. The extent of solubility of a substance in a specific solvent is measured as the saturation concentration where adding more solute does not increase its concentration in thesolution. The solvent is generally a liquid, which can be a pure substance or a mixture of two liquids. One may also speak of solid solution, but rarely of solution in a gas. The extent of solubility ranges widely, from infinitely soluble (fully miscible) such as ethanol in water, to poorly soluble, such as silver chloride in water. The term insoluble is often applied to poorly or very poorly soluble compounds. Solubility occurs under dynamic equilibrium, which means that solubility results from the simultaneous and opposing processes of dissolution and phase joining (e.g., precipitation of solids). Solubility equilibrium occurs when two processes proceed at a constant rate. Under certain conditions equilibrium solubility may be exceeded to give a socalled supersaturated solution, which ismetastable. Solubility is not to be confused with the ability to 
dissolve or liquify a substance, since these processes may occur not only because of dissolution but also because of chemical reaction. For example, zinc is insoluble in $\mathrm{HCl}$, but does dissolve in it chemically reacting into zinc chloride and hydrogen. Extensive use of solubility from different perspective has led to solubility being expressed in various manners. It is commonly expressed as a concentration, either by mass ( $\mathrm{g}$ of solute per $\mathrm{kg}$ of solvent, $\mathrm{g}$ per $\mathrm{dL}(100 \mathrm{~mL})$ of solvent), molarity, molality, mole fraction, or other similar descriptions of concentration. The maximum equilibrium amount of solute that can dissolve per amount of solvent is the solubility of that solute in that solvent under the specified conditions.

Solubility criteria

\begin{tabular}{|l|c|}
\hline $\begin{array}{l}\text { Descriptive } \\
\text { term }\end{array}$ & $\begin{array}{c}\text { Parts of solvent required for } \\
\text { one part of solute }\end{array}$ \\
\hline Very Soluble & Less than 1 part \\
\hline Freely Soluble 10 parts \\
\hline Soluble & 10 to 30 parts \\
\hline $\begin{array}{l}\text { Sparingly } \\
\text { Soluble }\end{array}$ & 30 to 100 parts \\
\hline $\begin{array}{l}\text { Slightly Soluble } \\
\text { Very Slightly } \\
\text { Soluble }\end{array}$ & 100 to 1000 parts \\
\hline $\begin{array}{l}\text { Practically } \\
\text { Insoluble }\end{array}$ & 1000 to 10,000 parts \\
\hline
\end{tabular}

Formulating poorly water soluble drug into a dosage form is always a challenging task because of the less solubility and dissolution related concern. To enhance the solubility of those drugs scientists over the world are inventing various approaches. Different ways to increase the solubility of poorly soluble drug is shown below for easy reference.

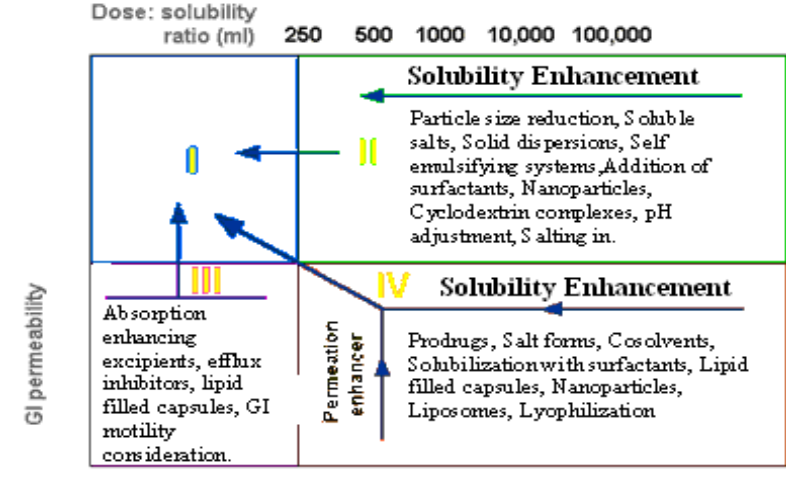

Different way to depict the solubility enhancement BCS classification

The introduction of Biopharmaceutics Classification
System (BCS) in 1995 was the result of continuous efforts in mathematical analysis for the elucidation of the kinetics and dynamics of the drug process in the gastrointestinal tract (GIT) for NDA (New Drug Application), ANDA (Abbreviated New Drug Application) filings and biowaivers.

The objectives of the BCS are:

- To improve the efficiency of the drug development and review process by recommending a strategy for identifying expensive clinical bioequivalencetest.

- To recommend a class of immediate-release (IR) solid oral dosage forms for which bioequivalence may be assessed based on invitro dissolutiontests.

- To recommend methods for classification according to dosage form dissolution along with the solubility-permeability characteristics of the drugproduct.

The BCS is a scientific framework for classifying a drug substance based on its aqueous solubility and intestinal permeability. It allows for the prediction of invivopharmacokinetics of oral immediate-release drug products by classifying drug compounds into four classes, depicted in table 1.2 based on their solubility related to dose and intestinal permeability in combination with the dissolution properties of the dosage form. Based on the intestinal permeability and solubility of drugs, Amidon developed Biopharmaceutical Classification System, which classifies the drugs into one of the fourgroups.

Biopharmaceutical classification system for drugs

\begin{tabular}{|c|c|c|c|c|}
\hline lass & $\begin{array}{c}\text { Solubili } \\
\text { ty }\end{array}$ & $\begin{array}{c}\text { Permeabi } \\
\text { lity }\end{array}$ & $\begin{array}{c}\text { Absorption } \\
\text { pattern }\end{array}$ & $\begin{array}{c}\text { Rate } \\
\text { limiting } \\
\text { step }\end{array}$ \\
\hline I & High & High & $\begin{array}{c}\text { Well } \\
\text { Absorbed }\end{array}$ & $\begin{array}{c}\text { Gastric } \\
\text { Emptying }\end{array}$ \\
\hline II & Low & High & Variable & $\begin{array}{c}\text { Dissolutio } \\
\mathrm{n}\end{array}$ \\
\hline II & High & Low & Variable & $\begin{array}{c}\text { Permeabili } \\
\text { ty }\end{array}$ \\
\hline IV & Low & Low & $\begin{array}{c}\text { Poorly } \\
\text { Absorbed }\end{array}$ & $\begin{array}{c}\text { Case by } \\
\text { case }\end{array}$ \\
\hline
\end{tabular}

The BCS Classification of a drug depends upon 3 key parameters that control absorption are solubility, dissolution rate and permeability. Biopharmaceutical Classification System categorized poorly soluble and highly permeable drugs under class II. Nearly $40 \%$ of 
the drug molecules that have been discovered are lipophilic in nature (Gulam M,2012).

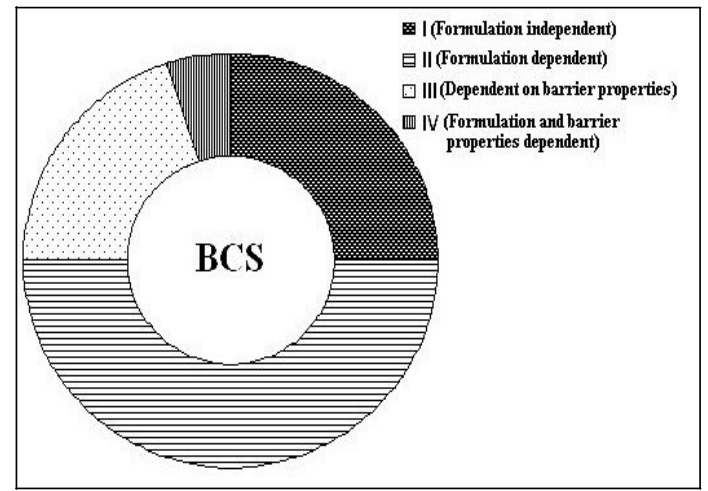

Graphical representation of distribution of drug candidates as per BCS

\section{Class I:}

The drugs of this class exhibit high absorption number and high dissolution number. The rate limiting step is drug dissolution and if dissolution is very rapid, then the gastric-emptying rate becomes the rate determining step. These compounds are well absorbed, and their absorption rate is usually higher than the excretion rate. Examples include Metoprolol,Diltiazem,Verapamil and Propranolol. The drugs belong to this class are not much dependent on formulationaspects.

\section{Class II:}

The drugs of this class have a high absorption number but a low dissolution number. Invivodrug dissolution is then a rate limiting step for absorption except at a very high dose number. The absorption for Class II drugs is usually slower than for Class I and occurs over a longer period of time. Invitro/invivocorrelation (IVIVC) is usually accepted for Class I and Class II drugs. The bioavailabilities of these products are limited by their solvation rates. Hence, a correlation between the invivobioavailability and the invitro solvation can be established. Examples include Glibenclamide, Phenytoin, Danazol, Mefenamic acid, Nifedinpine, Ketoprofen, Naproxen, Carbamezapine and Ketoconazole. The drugs belongs to this class are mainly dependent on formulation to enhance their solubility. The drugs under study in this research work are belongs to this class (Ritonavir andValsartan).

\section{Class III:}

Drug permeability is the rate limiting step for drug absorption, but the drug is solvated very quickly. These drugs exhibit a high variation in the rate and extent of drug absorption. Since the dissolution is rapid, the variation is attributable to alteration of physiology and membrane permeability rather than the dosage form factors. If the formulations does not change the permeability or gastrointestinal duration time, then the Class I criteria can be applied. Examples include Cimetidine, Ranitidine, Acyclovir, Neomycin B, Atenolol and Captopril. The drugs belongstothisclassaremainlydependentonbarrierproperti esastheyarelowpermeabledrugs.

\section{Class IV:}

The drugs of this class are problematic for effective oral administration. These compounds have poor bioavailability. Addition to this the compounds in class IV group have poor aqueous solubility also. They are usually not well absorbed through the intestinal mucosa and a highvariability is expected. Fortunately, extreme examples of Class IV compounds are the exception rather than the rule and these are rarely developed and marketed. Nevertheless, several Class IV drugs do exist. Examples include Hydrochlorothiazide, Taxol, Atorvastatin and Furosemide. Some literature says the drug Ritonavir, which is under this research work belongs to this class. Drugs belongs to this class mainly dependent on both formulation aspects and also on barrier properties as they are low soluble and low permeable drugs.

\section{Factors Affecting Solubility:}

Several factors affect solubility of a drug. The following are the factors that affect solubility.

ParticleSize

Temperature

Pressure

Nature of the solute andsolvent

Molecularsize

Polarity

Polymorphs

Solubility techniques:

Solubility improvement techniques can be categorized into physical modification, chemical modifications of the drug substance and other miscellaneous techniques.

\section{Physical Modification}

Particle size reduction like micronization and Nano ionization, modification of the crystal habit like polymorphs, amorphous form and co-crystallization, drug dispersion in carriers like eutectic mixtures, solid dispersions, solid solutions and cryogenic techniques.

\section{Chemical Modifications}

Change of $\mathrm{pH}$, use of buffer, derivatization, complexation and salt formation.

Miscellaneous Methods 
Supercritical fluid process, use of adjuvant like surfactant, solubilizers, co-solvency, hydrotropy and use of novel excipients.

\section{Nanosuspensions}

A pharmaceutical Nanosuspension is defined as very finely dispersed solid drug particles in an aqueous vehicle for either oral and topical use or parenteral and pulmonary administration, with reduced particle size, leading to an increased dissolution rate and therefore improved bioavailability. Nanosuspensions are colloidal dispersions and biphasic system consisting of drug particles dispersed in an aqueous vehicle in which the diameter of the suspended particle is less than $1 \mu \mathrm{m}$ in size. Nano ionization can be applied to most of the hydrophobic drug molecules to increase their solubility. Reduction of drug particles to nanometer range leads to an enhanced dissolution rate due to increased surface area and saturation solubility. Nano ionization acts by decreasing particle size and solvation energy of hydrophobic molecules. They are carrier free submicron colloidal drug delivery system containing surface active agents or polymeric stabilizers. An increase in the dissolution rate of micronized particles (particle size < $10 \mu \mathrm{m})$ is related to an increase in the surface area and consequently the dissolution velocity. Nanosized particles can increase solution velocity and saturation solubility because of the vapor pressure effect . Nanosuspensions have shown to be more cost effective and technically simple alternative particularly for poorly soluble drugs.

The particle size distribution of the solid particles in Nanosuspensions is usually less than one micron with an average particle size ranging between $200-600 \mathrm{~nm}$. Nanosuspension is a sub-micron colloidal dispersion of drug particles which are stabilized by surfactants, polymers or a mixture of both. This Nanosuspension formulation has a high drug loading, low incidence of sideeffectsbytheexcipientsandlowcost.Owing to the increased surface to volume ratio of the nanocrystals, an increase in saturated solubility and very fast dissolution rate can be seen, especially below particle sizes of $1 \mu \mathrm{m}$. Nanosuspension technology can also be used for drugs, which are insoluble in both water and organic solvents. Hydrophobic drugs such as Naproxen, Bupravaquone, Nimesulide, Amphotericin B, Omeprazole, Nifedipine are formulated as Nanosuspensions. The stability of the particles obtained in the Nanosuspension is attributed to their uniform particle size which is created by various manufacturing processes. The absence of particles with large differences in their size in Nanosuspensions prevents the existence of different saturationsolubilities and concentration gradients, consequently preventing the Ostwald ripeningeffect.

Ostwald ripening is responsible for crystal growth and subsequently formation of microparticles. It is caused by a difference in dissolution pressure/saturation solubility between small and large particles. Molecules diffuse from the higher concentration area around small particles which have higher saturation solubility to an area around larger particles possessing a lower drug concentration. This leads to the formation of a supersaturated solution around the large particles and consequently to drug crystallization and growth of the large particles.

\section{Preparation of Nanosuspension:}

Nanosuspensions have revealed their potential to tackle the problem associated with the delivery of poorly

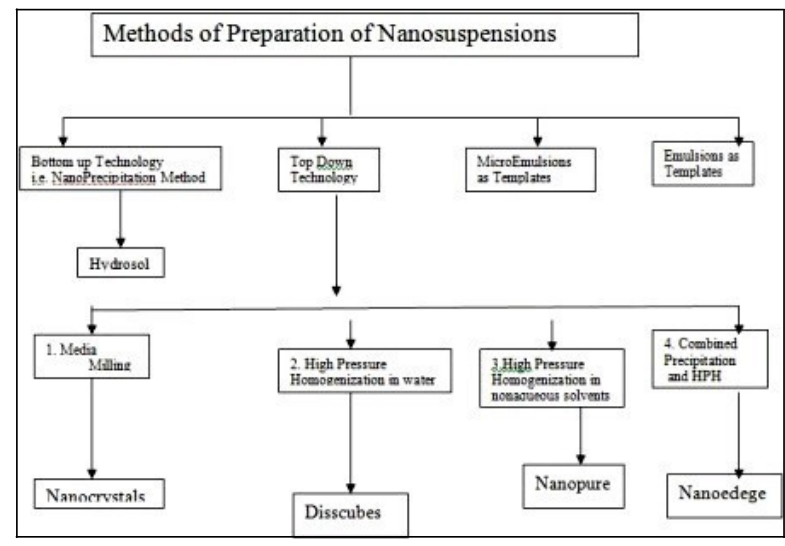

water soluble and lipid soluble drugs and are unique because of their simplicity and the advantage they confer over other strategies. The different ways of producing the Nanosuspensions are shown in below.

\section{MATERIALS \& METHODS:}

MATERIALS:

Materials: All the materials used in this dissertation belong to Mylan labs $\mathrm{R}$ and $\mathrm{D}$ Center, situated at Hyderabad, Telangana State. All the chemicals and solvents were of analytical reagent grade.

List of Materials

\begin{tabular}{|c|c|c|c|}
\hline $\begin{array}{c}\text { S.N } \\
\text { o. }\end{array}$ & $\begin{array}{c}\text { Name of } \\
\text { theingredients }\end{array}$ & Category & $\begin{array}{c}\text { Source/Suppl } \\
\text { ier }\end{array}$ \\
\hline 1 & Ritonavir & Drug & $\begin{array}{c}\text { Mylan Labs, } \\
\text { Hyderabad }\end{array}$ \\
\hline 2 & Valsartan & Drug & $\begin{array}{c}\text { Mylan Labs, } \\
\text { Hyderabad }\end{array}$ \\
\hline 3 & Poloxamer & Stabilizer & $\begin{array}{c}\text { BASF, } \\
\text { Germany }\end{array}$ \\
\hline
\end{tabular}




\begin{tabular}{|c|c|c|c|}
\hline 4 & Span 20 & Surfactant & \begin{tabular}{c} 
Croda, USA \\
\hline 5
\end{tabular} \\
Polplasdone XL-10 & $\begin{array}{c}\text { Superdisintegr } \\
\text { ant }\end{array}$ & $\begin{array}{r}\text { ISPchemical } \\
\text { LLC, } \\
\text { USA }\end{array}$ \\
\hline 6 & $\begin{array}{c}\text { Crosscarmellose } \\
\text { Sodium }\end{array}$ & $\begin{array}{c}\text { Superdisintegr } \\
\text { ant }\end{array}$ & $\begin{array}{c}\text { FMC BIO } \\
\text { POLYMER, }\end{array}$ \\
\hline 7 & $\begin{array}{c}\text { Sodium stearyl } \\
\text { fumarate }\end{array}$ & Lubricant & $\begin{array}{c}\text { JRS } \\
\text { PHARMA, } \\
\text { USA }\end{array}$ \\
\hline 8 & $\begin{array}{c}\text { MicrocrystallineCell } \\
\text { ulose }\end{array}$ & Diluent & $\begin{array}{c}\text { FMC BIO } \\
\text { POLYMER, }\end{array}$ \\
\hline 9 & Mannitol & Diluent & $\begin{array}{c}\text { ROQUETTE, } \\
\text { France }\end{array}$ \\
\hline 10 & Talc & Glidant & IMERYS, Italy \\
\hline 11 & Magnesium stearate & Lubricant & $\begin{array}{c}\text { Avantor } \\
\text { Performance } \\
\text { Material, USA }\end{array}$ \\
\hline
\end{tabular}

\section{Analytical methoddevelopment}

The present research work has been carried out with an aim to increase the solubility and dissolution rate of Ritonavir and Valsartan by Nanotechnology approach with poloxamer as stabilizing agent and further the optimized Nanosuspensions were formulated into tablets and capsules with suitable extragranular agents like microcrystalline cellulose/mannitol as diluent, cross carmellose sodium/polyplasdone $\mathrm{XL}-10$ as super disintegrant, span 20 as surfactant, talc/magnesium stearate/sodium stearyl fumerate as glidant/lubricant to improve the wettability and finally to improve the drug release characteristics for enhancing the bioavailability. Nanotechnology has shown to be more cost effective and technically simpler alternative, particularly for poorly water soluble drugs.

\section{Saturation solubility}

The solubility of drug is an important physicochemical property because it affects the bioavailability of the drug, the rate of drug release into dissolution medium and consequently, the therapeutic efficiency of the pharmaceutical product. The solubility of the molecules in various solvents is determined as a first step. This information is valuable in developing a formulation. Solubility was determined in solvents across biorelavent $\mathrm{pH}$ such as water and buffers prepared with variouspH.

Procedure: Solubility of Ritonavir/Valsartan in different buffers were determined by shake flask method. An excess amount of Ritonavir and Valsartan was added to each volumetric flask containing the selected buffer and mixed thoroughly. The volumetric flasks were then fixed onto a water bath shaker and shaken for $24 \mathrm{hrs}$ at $37^{\circ} \mathrm{C} \pm 1^{\circ} \mathrm{C}$. Samples were removed after the specified time and filtered through $0.45 \mu \mathrm{m}$ nylon 66 syringe driven membrane filter unit. The filtrates were then analyzed by UV spectrophotometer at $246 \mathrm{~nm}$ and 248nm respectively to evaluate the- amount of Ritonavir and Valsartan dissolved. Results are givenin table 5.8.

Drug Excipients compatibility:

\section{Physical observation}

Physical mixtures of Drug and excipients were prepared by grinding specific ratios (mentioned below in table 4.17) for drug and excipients in a mortar. Sample of 34grams was taken and loaded in a glass vial, covered with rubber stopper, sealed with aluminum cap and labeled properly. Samples were observed and the physical description was recorded for initial evaluation and loaded into stability chamber of $40^{\circ} \mathrm{C}$ and $75 \% \mathrm{RH}$ for 4 week to study compatibility of the drug with the selected excipients. At the end of $4^{\text {th }}$ week samples were removed, again observations were recorded to have a comparison with the Initial recorded observation. Results are given in table 5.9 and 5.10 for Ritonavir and Valsartanrespectively.

\section{Preparation of Ritonavir Nanosuspension}

Nanosuspension is a suspension containing the drug particles in nanosize range. For the present study, media milling by nanomill (Netzsch) was chosen for size reduction of Ritonavir drug particles as simple beaker method was not able to reduce the particle size of the molecule in the nanorange. The compositions of various trials undertaken are given.

Composition of Ritonavir Nanosuspensions

\begin{tabular}{|c|c|c|c|c|c|}
\hline \multirow{2}{*}{ S.No } & \multirow{2}{*}{$\begin{array}{c}\text { Ingredients } \\
(\mathbf{m g} / \mathbf{m l})\end{array}$} & \multicolumn{5}{|c|}{$\begin{array}{c}\text { Formulation } \\
\text { codes }\end{array}$} \\
\cline { 3 - 6 } & & $\mathbf{1}$ & $\mathbf{F 2}$ & F3 & $\mathbf{4}$ \\
\hline & Ritonavir & 00 & 00 & 00 & 00 \\
\hline \multirow{2}{*}{$\begin{array}{c}\text { Poloxamer F } \\
407\end{array}$} & - & 5 & 10 & 20 \\
\hline & Water & \multicolumn{4}{|c|}{$1 \mathrm{ml}$} \\
\hline
\end{tabular}

Manufacturing procedure for the preparation of Ritonavir Nanosuspension:

The poloxamer was dissolved in required quantity of water and stirred to get clear solution. Then Ritonavir was added to the poloxamer solution and stirring was continued for $30 \mathrm{~min}$. The resultant dispersion was passed through colloidal mill for about $15 \mathrm{mins}$ to get the homogenous smooth dispersion. The resultant 
dispersion was passed through Nanomill till particles of desired size range were obtained.

Media milling: Freshly prepared dispersion of the Ritonavir drug was placed in nanomill container. The milling chamber was charged with milling media (Zirconium Oxide Beads)then rotated at a very high shear rate under controlled temperatures for several hours. The high energy shear forces are generated as a result of the impaction of the milling media with the dispersed drug resulting into breaking of microparticulate drug into Nanoparticulate drug. Inbetween samples were collected for the physical characterization of the sample. Various process parameters like volume of beads, stirring time and stirring speed were carefully monitored and optimized parameters were maintained for the formulation of Ritonavir Nanosuspension. The optimized milling parameters maintained during manufacturing of Ritonavir Nanosuspensions are given. All optimization study results are given.

Milling parameters for Ritonavir Nanosuspensions

\begin{tabular}{|c|c|c|c|c|c|}
\hline $\begin{array}{l}\mathrm{S} . \\
\mathrm{N} \\
\mathbf{0}\end{array}$ & $\begin{array}{c}\text { Formulatio } \\
\text { ns }\end{array}$ & $\begin{array}{c}\text { Agitatio } \\
n \\
\text { (rpm) }\end{array}$ & \begin{tabular}{|c} 
Pressur \\
e \\
bar $)$
\end{tabular} & $\begin{array}{c}\text { Pump } \\
\text { speed(rp } \\
\text { m) }\end{array}$ & $\begin{array}{c}\text { ime } \\
\text { (hours } \\
\text { ) }\end{array}$ \\
\hline 1. & $\mathrm{~F} 1$ & 3000 & $0.2-2$ & 60 & $1-4$ \\
\hline 2. & F2 & 3000 & $0.2-2$ & 60 & $1-4$ \\
\hline 3. & F3 & 3000 & $0.2-2$ & 60 & $1-4$ \\
\hline 4. & F4 & 3000 & $0.2-2$ & 60 & $1-4$ \\
\hline
\end{tabular}

\section{Preparation of Valsartan Nanosuspension:}

Valsartan Nanosuspension was prepared by simple beaker method zirconium beads as milling media. The initial predispersion of Valsartan and polymer was passed through colloidal milltoensure particle homogeneity. Various process parameters like volume of beads, stirringtime and stirring speed were carefully monitored and optimized parameters were maintained for the formulation of Valsartan Nanosuspension. Valsartan microsuspension was also prepared with the same procedure till colloidal milling and conventional tablets were prepared by granulation with the help of extragranular tableting excipients with Valsartan microsuspension as granulating fluid. The resultant wet mass was dried and compressed into tablets using $10 \mathrm{~mm}$ standard round concave punches using Cadmach 8 station compression machine. These tablets were prepared to have comparison, during evaluation of Valsartan Nanotablets. The formula for the same is given.
Composition of Valsartan Nanosuspensions

\begin{tabular}{|l|l|l|l|l|l|}
\hline \multirow{2}{*}{$\begin{array}{l}\text { Ingredients } \\
(\mathbf{m g} / \mathbf{m} \mathbf{l})\end{array}$} & \multicolumn{5}{|l|}{ Formulation code } \\
\cline { 2 - 7 } & $\mathbf{F 3}$ & $\mathbf{F 4}$ & $\mathbf{F 5}$ & $\mathbf{F 6}$ & $\mathbf{F 7}$ \\
\hline Valsartan & 80 & 80 & 80 & 80 & 80 \\
\hline $\begin{array}{l}\text { Poloxamer } \\
407\end{array}$ & 8 & 16 & 24 & 32 & 40 \\
\hline Water & 1 & 1 & 1 & 1 & 1 \\
\hline
\end{tabular}

Manufacturing procedure for the preparation of Valsartan Nanosuspension:

The poloxamer was dissolved in required quantity of water and stirred to get clear solution. Then Valsartan was added to the poloxamer solution and stirring was continued for 30mins. This initial predispersion of Valsartan was passed through colloidal mill for $15 \mathrm{mins}$ to get the homogenous smooth dispersion. The resultant dispersion wasNanonised with the help of beaker method and zirconium beads as milling media. for 24hrs. The compositions of various trials are givenbelow.Periodically samples were collected for physical characterization and evaluation. Various process parameters like volume of beads, stirring time and stirring speed were carefully monitored and optimized parameters maintained for the formulation of Valsartan Nanosuspension. The mechanism of size reduction remains same as mentioned in Ritonavir Nanosuspension.

Milling parameters for Valsartan
Nanosuspensions:

\begin{tabular}{|c|c|c|c|c|}
\hline S.N & Formulat & VolumeofBea & Agitationspee & Time( \\
\hline o. & ions & $\mathrm{ds}(\mathrm{ml})$ & $\mathrm{d}(\mathrm{rpm})$ & hrs) \\
\hline 1 & F3 & 60 & 800 & $1-24$ \\
\hline 2 & $\mathrm{~F} 4$ & 60 & 800 & $1-24$ \\
\hline 3 & F5 & 60 & 800 & $1-24$ \\
\hline 4 & F6 & 60 & 800 & $1-24$ \\
\hline 5 & F7 & 60 & 800 & $1-24$ \\
\hline
\end{tabular}

\section{EVALUATION OFNANOSUSPENSIONS:}

A. Physicalevaluation:

- Appearance ofphases

- Particle sizeanalysis

- Zetapotential

- X-ray diffractionstudies

- Differential ScanningCalorimetry

- Saturation solubilitystudies

- Microscopy test andSEM

- Freeze-Thawstudy 
- Fourier Transform Infrared Spectroscopy(FTIR)

B. Flowproperties:

- Sedimentationvolume

- Pourability

- Redispersibility

C. Chemicalevaluation:

- Assay

- Dissolution

- Relatedsubstances

\section{RESULTS \& DISCUSSION:}

An increased demand for more patient friendly dosage forms has been observed since past few years. The oral route of drug administration is the most preferred method of delivery due to convenience and ease of ingestion. Our research in the field of Nanosuspension formulation is focused on media milling methodwhich comes under top down technology. This is a disintegration approach from large particles, microparticles to Nanoparticles. From a patient's perspective swallowing a dosage form is a comfortable and a familiar means of taking medication. Although oral route of administration is preferred for many drugs it can be a problematic and inefficient mode of delivery for a number of reasons. Limited drug absorption results in poor bioavailability and is most common among the problems that can be encountered when delivering an active agent via oral route. Drug absorption from the gastro intestinal tract can be limited by various factors with the most common one being poor aqueous solubility and poor permeability of a drug molecule. When delivering an active ingredient orally, it must first dissolve in gastrointestinal fluids before it can permeate the membranes of the gastro intestinal tract to reach systemic circulation. Therefore, a drug with poor aqueous solubility will exhibit dissolution rate limited absorption. The dissolution rate of poorly water soluble drugs often becomes a rate limiting step in their absorption form GI tract. Solubility behavior of a drug plays a key role for its oral bioavailability. For some drugs solubility presents a challenge to the development of a suitable formulation for oraladministration.

The present research work has been carried out with an aim to increase the solubility and dissolution rate of Ritonavir and Valsartan by formulating them into a Nanosuspension. Further optimized Nanosuspensions were formulated as tablets and capsules to make the formulations stable and patient friendly. Ritonavir and Valsartan Nanosuspensions were prepared by pearl milling technique using Zirconium beads as milling media and Poloxamer 407 as stabilizer.

Preparation of Nanosuspensions:

Formulation parameters of Ritonavir Nanosuspension:

\begin{tabular}{|c|c|c|c|c|c|c|}
\hline $\begin{array}{c}\text { S.N } \\
\text { o }\end{array}$ & $\begin{array}{l}\text { Formulat } \\
\text { ion code }\end{array}$ & $\begin{array}{c}\mathrm{Ti} \\
\mathrm{me}\end{array}$ & $\left|\begin{array}{c}\text { Agitati } \\
\text { on } \\
\text { speed }\end{array}\right|$ & $\begin{array}{c}\text { Partic } \\
\text { le } \\
\text { size } \\
(\mathrm{nm})\end{array}$ & $\begin{array}{c}\text { Polydisper } \\
\text { sity Index } \\
\text { (PDI) }\end{array}$ & Remarks \\
\hline 1 & $\mathrm{~F} 1$ & $\begin{array}{c}4 \mathrm{hr} \\
\mathrm{s}\end{array}$ & 3000 & - & - & \begin{tabular}{|} 
Drug could \\
notbe \\
dispersedprop \\
erly.
\end{tabular} \\
\hline 2 & F2 & $\begin{array}{c}4 \mathrm{hr} \\
\mathrm{s}\end{array}$ & 3000 & 456 & 0.424 & $\begin{array}{c}\text { Stabilizer } \\
\text { concentration } \\
\text { was } \\
\text { insufficient }\end{array}$ \\
\hline 3 & F3 & $\begin{array}{c}4 \mathrm{hr} \\
\mathrm{s}\end{array}$ & 3000 & 384 & 0.266 & $\begin{array}{l}\text { Dispersion of } \\
\text { drug in the } \\
\text { polymer is } \\
\text { good }\end{array}$ \\
\hline 4 & F4 & $\begin{array}{c}4 \mathrm{hr} \\
\mathrm{s}\end{array}$ & 3000 & 356 & 0.289 & $\begin{array}{c}\text { High quantity } \\
\text { of foam } \\
\text { Generation. } \\
\text { Dispersion of } \\
\text { drug in the } \\
\text { polymeris } \\
\text { good }\end{array}$ \\
\hline
\end{tabular}

Formulation F1 was not suitable for milling as the drug could not be dispersed properly for the purpose of milling. In case of F2 the poloxamer concentration was insufficient to effectively disperse the drug and in F4 too high concentration of poloxamer caused much foam. F3 was selected for further studies as there was less foaming and greater stability of the Ritonavir Nanosuspension which is indicatedby least PDI. All the details are given. 


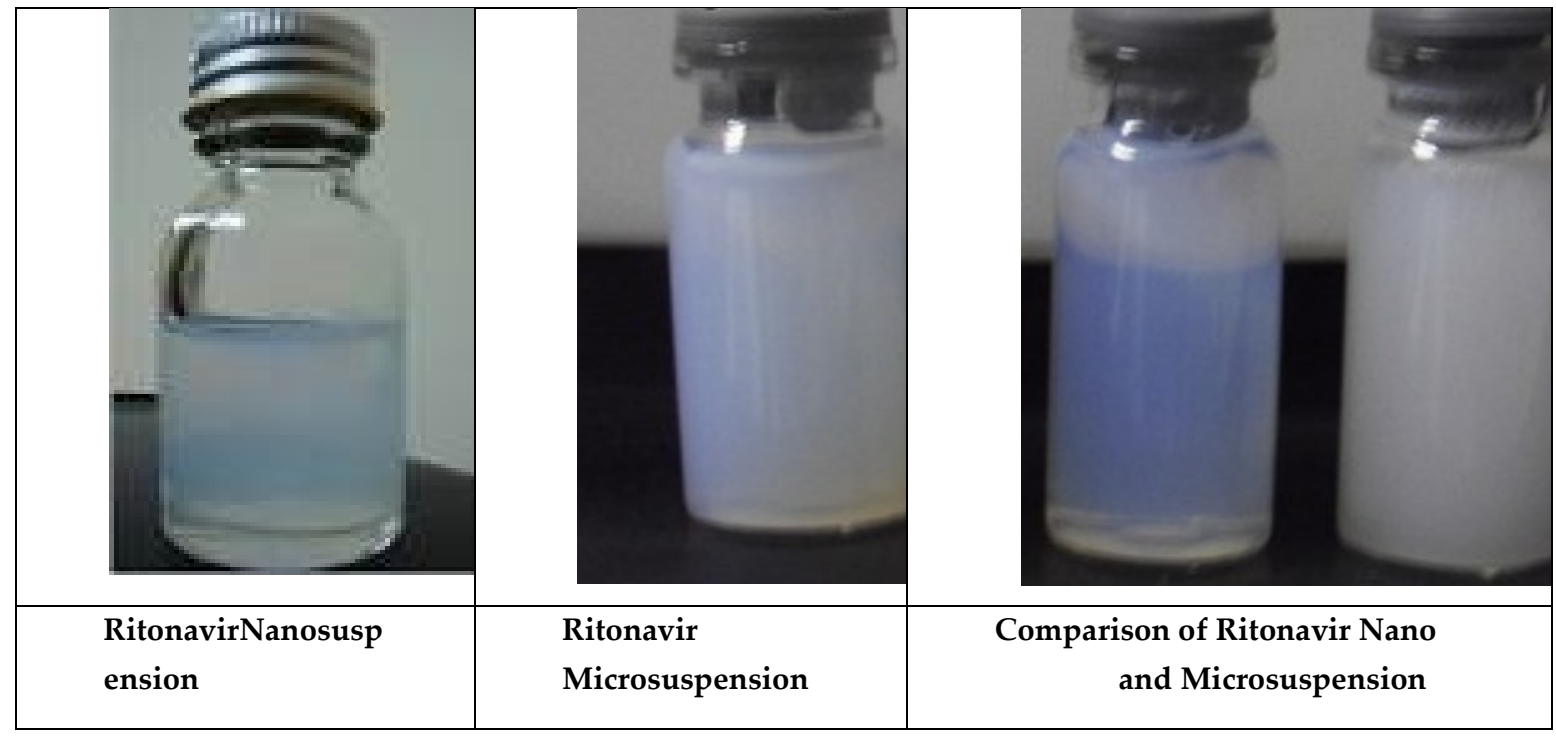

Pictures showing Ritonavir Nanosuspension and Microsuspension

The prepared Ritonavir Nanosuspension exhibited tense bluish opalescence, indicating successful formation of the Nanosuspension of Ritonavir. The Ritonavir Nanosuspension was transparent whereas the microsuspension was turbid which is shown.

Optimization of Process Parameters for Ritonavir Nanosuspension:

Optimization of milling media volume for Ritonavir

\begin{tabular}{|l|l|l|l|l|}
\hline S. No. & $\begin{array}{l}\text { Volume of milling } \\
\text { media }(\mathrm{ml})\end{array}$ & PDI & PSD (nm) & $\begin{array}{l}\text { Agitation } \\
\text { speed }\end{array}$ \\
\hline 1 & 50 & 0.562 & 652 & 3000 \\
\hline 2 & 60 & 0.266 & 384 & 3000 \\
\hline 3 & 70 & 0.326 & 435 & 3000 \\
\hline
\end{tabular}

Optimization of milling speed for Ritonavir

\begin{tabular}{|l|l|r|l|}
\hline S. No. & Time & Milling Speed & PSD (nm) \\
\hline 1 & 4 & 2500 & 512 \\
\hline 2 & 4 & 3000 & 384 \\
\hline 3 & 4 & 3500 & 370 \\
\hline
\end{tabular}

By keeping the time and agitation speed constant, volume of milling media was optimized. $60 \%$ volume of milling media was found to be appropriate as it gave minimum particle size distribution. PDI was found to be better with $60 \mathrm{ml}$ of milling media compared to that of $50 \mathrm{ml}$ and $70 \mathrm{ml}$ of media. At $60 \mathrm{ml}$ milling media the particle size of the Nanosuspension produced was also found to be very less. Hence $60 \mathrm{ml}$ milling media was finalized for further optimization trials. The minimum PDI signifies the uniform distribution of the particles and stability of the Nanosuspension produced. By varying the speed of the mill, there was no much impact was found on particle size of the formulation. Hence milling speed of 3000rpm was finalized for further optimization trials. All the corresponding values are given.

Formulation parameters for Valsartan Nanosuspension

\begin{tabular}{|r|r|r|r|r|r|r|}
\hline S.No. & Formulation code & Time & $\begin{array}{c}\text { Speed } \\
(\mathrm{rpm})\end{array}$ & $\begin{array}{c}\text { Particle size } \\
(\mathrm{nm})\end{array}$ & $\begin{array}{l}\text { Polydispersity } \\
\text { Index }\end{array}$ & Remarks \\
\hline 1 & F3 & $24 \mathrm{hrs}$ & 750 & - & & Formation of \\
\hline
\end{tabular}




\begin{tabular}{|r|r|l|l|l|l|l|}
\hline 2 & F4 & $24 \mathrm{hrs}$ & 750 & 219 & 0.457 & $\begin{array}{l}\text { Dispersion of drug in } \\
\text { the polymer is good }\end{array}$ \\
\hline 3 & F5 & $24 \mathrm{hrs}$ & 750 & 43 & 0.366 & $\begin{array}{l}\text { Dispersion of drug in } \\
\text { the polymer is good }\end{array}$ \\
\hline 4 & F6 & $24 \mathrm{hrs}$ & 750 & 422 & 0.488 & $\begin{array}{l}\text { Dispersion of drug in } \\
\text { the polymer is good }\end{array}$ \\
\hline 5 & F7 & $24 \mathrm{hrs}$ & 750 & - & $\begin{array}{l}\text { Viscosity of suspension } \\
\text { was found to be more }\end{array}$ \\
\hline
\end{tabular}

As Valsartan drug was found to be softer in nature compared to Ritonavir, a simpler method like beaker method was adopted for media milling technique. The mechanism of size reduction remains same. In Valsartan Nanosuspension formulation F3, formation of hard sediment was observed which may be due to insufficient concentration of polymer as dispersing agent. In formulation F7, the solution resulted in higher viscosity may be due to high concentration of poloxamer 407. Theformulations F4, F5 \&F6 resulted in good Nanosuspension with particle size of $219 \mathrm{~nm}, 43 \mathrm{~nm}$ and $422 \mathrm{~nm}$ respectively. The particle size obtained with formulation F5 was found to be least, $43 \mathrm{~nm}$. Hence F5 formulation was used for further optimization trials of Valsartan. The details of all trials are given below.
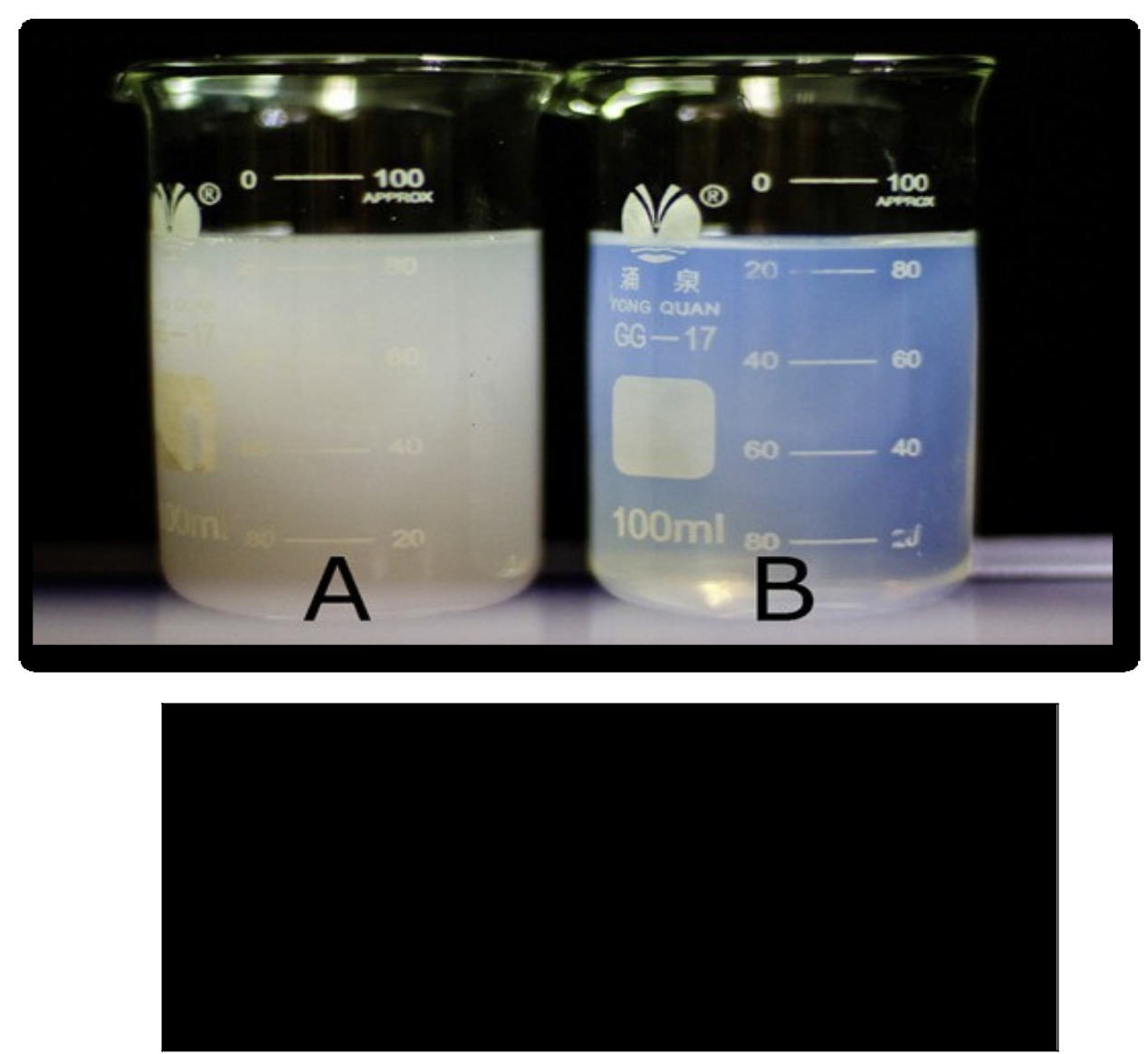

Pictures showing Valsartan Microsuspension (A) and Nanosuspension (B)

The prepared Valsartan Nanosuspension exhibited tense bluish opalescence, indicating successful formation of the Nanosuspension of Valsartan. The Valsartan Nanosuspension was transparent whereas the microsuspension was turbid which is shown below. 
Optimization of process parameters for Valsartan Nanosuspension:

Optimization of milling media volume for Valsartan

\begin{tabular}{|c|c|c|c|c|}
\hline S. No. & $\begin{array}{c}\text { Volume of milling } \\
\text { media (ml) }\end{array}$ & PDI & $\begin{array}{c}\text { PSD } \\
(\mathbf{n m})\end{array}$ & $\begin{array}{c}\text { Agitation } \\
\text { speed }\end{array}$ \\
\hline 1 & 40 & 0.655 & 723 & 750 \\
\hline 2 & 50 & 0.412 & 224 & 750 \\
\hline 3 & 60 & 0.224 & 43 & 750 \\
\hline 4 & 70 & 0.286 & 56 & 750 \\
\hline
\end{tabular}

Optimization of milling speed for Valsartan

\begin{tabular}{|l|l|l|l|}
\hline S. No. & Time & Milling speed & PSD ofFormulation \\
\hline 1 & 24 & 750 & 43 \\
\hline 2 & 24 & 1000 & 52 \\
\hline 3 & 24 & 1200 & 58 \\
\hline
\end{tabular}

The particle size and PDI was found to be better with $60 \mathrm{ml} / 70 \mathrm{ml}$ of milling media compared to that of $40 \mathrm{ml}$ and $50 \mathrm{ml}$ of media. At $60 \mathrm{ml}$ media the particle size of the Nanosuspension produced was also found to be very less. Hence $60 \mathrm{ml}$ media was finalized for further trials. By varying the speed of the mill, not much impact was found on particle size of the formulation. Hence milling speed of 750rpm was finalized for further optimization trials of Valsartan. All the corresponding results are given below.

\section{EVALUATION OF NANOSUSPENSION:}

\section{Particle Size Distribution Analysis by Malvern particle size analyzer:}

The mean particle size and particle size distribution are two important characteristic parameters because they affect the saturation solubility, dissolution rate, physical stability even invivobehavior of Nanosuspensions. The polydispersity index (PDI) is an important parameter that governs the physical stability of Nanosuspensions and should be as low as possible for long term stability of Nanosuspensions. A PDI value of 0.1 to 0.25 indicates a fairly narrow size distribution.

Particle size analysis of Ritonavir Nanosuspensions

\begin{tabular}{|c|c|c|c|c|c|c|c|}
\hline \multirow[b]{2}{*}{$\begin{array}{l}\text { S. } \\
\text { No. }\end{array}$} & \multirow[b]{2}{*}{$\begin{array}{l}\text { Time } \\
\text { (min) }\end{array}$} & \multirow{2}{*}{$\begin{array}{l}\text { Mill speed } \\
\text { rpm }\end{array}$} & \multirow{2}{*}{$\begin{array}{l}\text { Pump } \\
\text { rpm }\end{array}$} & & \multicolumn{3}{|c|}{ Average Particle size (nm) } \\
\hline & & & & & \multicolumn{2}{|c|}{ Before drying } & $\begin{array}{l}\text { After drying and } \\
\text { redispersion }\end{array}$ \\
\hline \multicolumn{4}{|c|}{ Batch no of the formulations } & F2 & F3 & F4 & F3 \\
\hline & 60 & 3000 & 70 & 950.4 & 864.8 & 870.6 & 850.3 \\
\hline & 120 & 3000 & 70 & 790.4 & 633.7 & 694.4 & 646.8 \\
\hline & 180 & 3000 & 70 & 610.3 & 425.4 & 4990.5 & 420.1 \\
\hline & 240 & 3000 & 70 & 517.4 & 384.6 & 418.0 & 408.2 \\
\hline
\end{tabular}

Particle size distribution of Ritonavir Nanosuspension F3

Effect of milling time on particle size was optimized by keeping the speed and milling media volume constant, using $0.4 \mathrm{~mm}$ of zirconium oxide beads. The particle size of the Nanosuspension formulations were evaluated by Malvern particle size analyzer (Zetasizer) and the results showed that the particle size of formulations F2 (Drug: Poloxamer 1:0.05), F3 (Drug: Poloxamer - 1:0.1) and F4 (Drug: Poloxamer - 1:0.2) were reduced to nanometric range. The particle size distribution of formulation F3 was found to be around 400nm with polydispersity index of 0.268 . Hence the formulation F3 with ratio of Ritonavir: poloxamer (1:0.1) was used for further formulation development of Ritonavir Capsules/Tablets. Particle size determination was also performed after drying the Nanosuspension and then redispersion of same dried Nanosuspension in water and Z-avg was found to be slightly higher when compared to the Nanosuspension prepared freshly. All the corresponding results are given in table 5.17. . However the difference in particle size results obtained found to be negligible when compared with each other (Fresh Nanosuspension and Dried Nanosuspension). There was no significant change in particle size distribution on dilution of the Nanosuspension. The 
results are given in table 5.18. PDI values were not altered after dilution which shows that the particles are within narrow size range. After 4 weeks all the above Nanosuspension formulations ( F2, F3, F4) were again tested for particle size distribution to check whether any cluster/growth/ agglomeration and found to be 530, 377, 429nm respectively. The physical stability study results of F2 (Drug: Poloxamer - 1:0.05), F3 (Drug: Poloxamer - 1:0.1) and F4 (Drug: Poloxamer 1:0.2) at room temperature for 1 month was found to be satisfactory. Sedimentation of suspension was observed after 2weeks for F2 (Drug: Poloxamer- 1:0.05) and no sedimentation was observed after 2 weeks and a slight sedimentation was observed after 4 weeks for formulations F3 (Drug: Poloxamer - 1:0.1) and F4 (Drug: Poloxamer - 1:0.2), which were readilyredispersible.

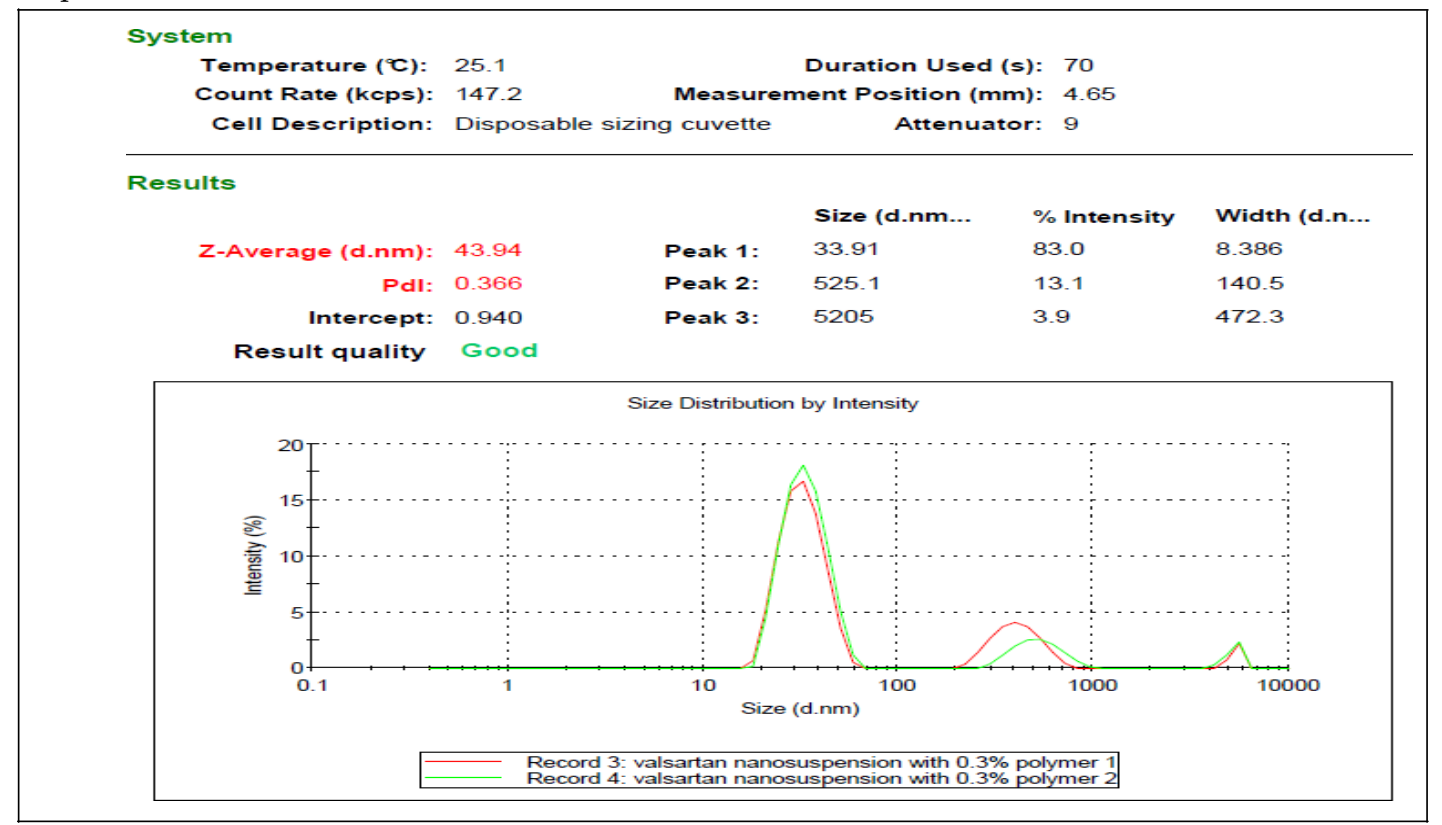

Particle size distribution of Valsartan Nanosuspension F5

Effect of milling time on particle size was optimized by keeping the speed and milling media volume constant using $0.4 \mathrm{~mm}$ of zirconium oxide beads. The particle size of the Nanosuspension formulations were evaluated by Malvern particle size analyzer (Zetasizer) and the results showed that the particle size of formulations F4 (Drug: Poloxamer - 1:0.2), F5 (Drug: Poloxamer - 1:0.3) and F6 (Drug: Poloxamer - 1:0.4) were reduced to Nanometric range. The particle size distribution of formulation F5 was found to be 43nm with polydispersityindex of 0.366 . Hence the formulation F5 with ratio of Valsartan: poloxamer (1:0.3) was used for further formulation of Valsartan tablets. The Valsartan Nanosuspension F5 was dried and again redispersed in water and PSD was measured to see any effect of drying and redispersion. All the corresponding results are tabulated in table 5.19. There was no significant change in particle size distribution on dilution of the Nanosuspension. The results are given in table 5.20. After 4 weeks all the above Nanosuspension formulations (F4, F5, F6) were again tested for particle size distribution to check whether any cluster/growth/agglomeration and found to be 265, 45, 240nm respectively. The physical stability study results of F4 (Drug: Poloxamer - 1:0.2), F5 (Drug: Poloxamer - 1:0.3) and F6 (Drug: Poloxamer - 1:0.4) at room temperature for 1 month was found to be satisfactory. No sedimentation of suspension was observed after 2weeks and a slight sedimentation was observed after 4 weeks for formulations F4 (Drug: Poloxamer - 1:0.2) and F6 (Drug: Poloxamer - 1:0.4) which was readily redispersible. There was no sedimentation observed with the formulation F5 (Drug: Poloxamer -1:0.3).

\section{Saturation Solubility:}

Saturation solubility of Ritonavir and Valsartan API in different media before and after Nanosuspension formulation

\begin{tabular}{|l|l|l|l|l|}
\hline \multirow{2}{*}{ Solvent } & Ritonavir & Nano Suspension & Pure drug & Nano suspension \\
\cline { 2 - 5 } & Pure drug & & 1.621 & 0.422 \\
\hline Water & 0.1568 & 5.125 \\
\hline
\end{tabular}




\begin{tabular}{|l|l|l|l|l|}
\hline $\mathrm{pH} 1.2$ & 0.2637 & 3.521 & 0.081 & 0.93 \\
\hline $\mathrm{pH}$ 4.5 Acetate buffer & 0.0568 & 0.924 & 0.923 & 12.52 \\
\hline $\mathrm{pH}$ 6.8 Phosphate buffer & 0.0284 & 0.834 & 1.321 & 16.36 \\
\hline $\mathrm{pH}$ 7.4 buffer & 0.0426 & 0.921 & 1.384 & 17.52 \\
\hline
\end{tabular}

Tremendous fold of increase in saturation solubility was observed when both the investigational drugs were formulated into Nanosuspension. This may be due to Increase in surfaceareaofthedrugsbecauseofNano ionization .Thefinenessofthedispersedparticlescausesthem to dissolve more quickly owing to their higher dissolution pressure and leads to an increased saturation solubility. This may enhance bioavailability of drugs compared to other microparticular systems. The results are given below.

\section{SUMMARY \&CONCLUSION ;}

Saturated solubility studies performed on Ritonavir and Valsartan API in micronized form. The study found to exhibit highest solubility in $1.2 \mathrm{pH} \mathrm{HCl}$ (for Ritonavir) and $6.8 \mathrm{pH}$ phosphate buffer (for Valsartan). Hence same medias were selected as a dissolution media for furtherstudies. In the present investigation, an attempt was made to formulate Ritonavir and Valsartan Nanosuspension using poloxamer as dispersing/stabilizing agent with the use of media millingtechnique. The preformulation studies were done initially, which include determination of flow properties (bulk density, Tapped density, Carr's index, Hauser's ratio and angle of repose), particle size distribution, saturation solubility studies, drug-excipient compatibility study. From the data it was inferred that Ritonavir/Valsartan both molecules has passable flow properties. From the stability studies by DSC analysis, it was reasonable to believe that there was no interaction between drug and excipients used in Nano ionization process used in Ritonavir/Valsartan Nanosuspensionpreparation. The results of drug excipients compatibility studies suggest that there was no significant change in the physical appearance of premixture blends, when stored at $40^{0} \mathrm{C} / 75 \% \mathrm{RH}$ for a period of 4 weeks when compared to initialsample. Different batches were taken to reduce the particle size of drug by changing the milling speed and volume of milling beads volume by keeping size of the bead and time duration for Nano ionization cycle as constant. Bead size of 0.4 microns and milling time of $4 \mathrm{hrs}$ produced particles of $400 \mathrm{~nm}$ size range when operated at a milling speed of 3000rpm with $60 \%$ volume of milling media. The Ritonavir Nanosuspension thus produced did not show any stability related problems when stored for 1 month at $40^{0} \mathrm{C} / 75 \%$ RH. For Valsartan because of softer nature of drug molecule, a simpler beaker method was adopted and bead size of 0.4 microns and milling time of $24 \mathrm{hrs}$ produced particles of $43 \mathrm{~nm}$ size range when operated at a milling speed of $750 \mathrm{rpm}$ with $60 \%$ volume of milling media. Valsartan Nanosuspension thus produced did not show any stability related problems when stored for 1 month at $40^{0} \mathrm{C} / 75 \% \mathrm{RH}$. The optimized Ritonavir Nanosuspension was converted into solid dosage form by drying the Nanosuspension in VTD at $60^{\circ} \mathrm{C}$ till the LOD limit of NMT 2.5\% was achieved. Then suitable extra granular ingredients were added and converted into capsule dosage form and tablet dosage form to make it more patientfriendly. Saturated solubility studies were again performed on optimized Ritonavir / Valsartan Nanosuspension. Tremendous increase in solubility in all the medias which were tried on plain micronized drug. This may be due to increase in surface area of the drug due to Nano ionization process. The Dissolution study profiles of micronized drug in suspension and Nanonised drug in suspension was compared and remarkable improvement was found for Nanonised drug in selected media for bothRitonavir/Valsartan. The average particle size of the Ritonavir optimized Nanosuspension thus produced was found to be about 400nm with PDI of 0.268 indicating good physical stability of Nanosuspension. The average particle size of the Valsartan optimized Nanosuspension thus produced was found to be $43 \mathrm{~nm}$ with PDI of 0.366 indicating good physical stabilityof Nanosuspension. The zeta potential of $-25.4 \mathrm{mV}$ for optimized Ritonavir Nanosuspension indicates the good physical stability of Nanosuspensionproduced. The zeta potential of $19.5 \mathrm{mV}$ for optimized Valsartan Nanosuspension 
indicates the good physical stability of Nanosuspensionproduced. The availability of characteristic peaks of Ritonavir in Ritonavir Nanosuspension reveals that the original crystal habitat of the Ritonavir drug before Nano ionization is not been changed. Because of interference of XRD spectrum of poloxamer, the XRD studies could not be used to determine the crystalline form of Valsartan molecule inNanosuspension. In DSC the two melting transitions in the system made up of drug (Ritonavir or Valsartan) and poloxamer signifies there is no interaction between drug (Ritonavir or Valsartan) and poloxamer. The optical microscopic images and SEM images reveals of great difference between Ritonavir/Valsartan suspension and Nanosuspension. The small uniform regular shaped particles are the outcome of nanotechnologyapproach. Freeze thaw study and evaluation after freeze thaw study reveals good physical stability of Ritonavir/ValsartanNanosuspension. The drug content of Ritonavir/Valsartan in optimized Nanosuspensions were found to be in the range of 99.5 to 99.9 / 98.6 to99.2 The FTIR study also indicating that there is no interaction between Ritonavir/Valsartan drug substance and poloxamer due to Nano ionization process. The Dissolution of Ritonavir Nanosuspension found to be $87 \%$ in selected dissolution media when compared to the dissolution of 41.6 and $56 \%$ corresponding to Ritonavir plain drug and Ritonavir suspension. Based on this invitro dissolution study it is evident that Ritonavir Nanosuspension exhibit high dissolution rate and extent probably due to increase in surface area because of Nano ionization. Hence this Nanosuspension was further selected for preparation of Ritonavir capsules and tablets with the help of suitable capsulating and tabletingagents. The Extent of drug release in Ritonavir Nanocapsule/Nanotablets produced by using optimized Ritonavir Nanosuspension were found to be inbetween 88 to $98 \%$ (for capsules) and90to98\%(fortablets)whencomparedto99.8\%ofIn novatorproductNorvircapsules. The Dissolution of Valsartan Nanosuspension found to be $98 \%$ in finalized dissolution media when compared to the dissolution of 22 and $25 \%$ corresponding to Valsartan plain drug and Valsartan suspension.
Based on this invitro dissolution study it is evident that the Valsartan Nanosuspension exhibit high dissolution rate and extent probably due toincrease in surface area because of Nano ionization. Hence this Nanosuspension was further selected for preparation of Valsartan Nanotablets with the help of suitable tableting agents. The Valsartan Nanotablets produced by top spraying optimized Valsartan Nanosuspension on tableting excipients with the help of GPCG 1.1 and Valsartan Nanotablets produced by simple granulation technology in RMG was found to be better in in drug release in rate and extent when compared to the Innovator product DiovanTablet. The extent in drug release in Valsartan tablets produced by Nanotechnology approach

was foundtobe91.1\%and $99.6 \%$ whencomparedto79\%of Reference product Diovantablet. All the Ritonavir/Valsartan Nanotablets found to be stable and meeting the specified limits for Average weight, Friability, DT and drugcontent. Accelerated stability studies indicated that there is no visible physical change observed in the optimized formulations after storage. No significant changes observed in drug release pattern during stability studies on optimized Ritonavir/Valsartan Nanosuspension /Nanocapsule / Nanotablet formulation. The related substance data were also found to be comparable when compared to the initialdata. The relative bioavailability of Ritonavir Nanosuspension (RNS) was found to be $150 \%$ when compared to Ritonavir micronized suspension. (RMS). This can be attributed to enhanced surface area due to Nanonising and improved dissolution rate andextent. The relative bioavailability of Valsartan Nanosuspension (VNS) was found to be $278 \%$ when compared to Valsartan micronized suspension. (VMS). This can be attributed to enhanced surface area due to Nanonising and improved dissolutionrate. A significant increase in bioavailability data was found in Valsartan compared to Ritonavir Nanosuspension. This may be attributed to the BCS class of the drug. Valsartan belongs to class II as per BCS where as Ritonavir belongs to class II and IV as perliterature. All the Ritonavir optimized formulations (Nanosuspension, capsule and tablet dosage form) found to follow the first 
order kinetics indicating that the drug release rate is concentration dependent with R2 values of 0.959, 0.983, 0.984respectively. The Valsartan Optimized formulations (Tablet dosage form) found to follow first order model kinetics with R2 values of 0.980 and 0.979 respectively for optimizedValsartanNanotablets produced by two different approaches. Valsartan optimized Nanosuspension formulation found to follow first order model kinetics as R2 values were found to be 0.853 . The results of the present investigation clearly indicated that the preparation of Nanosuspension greatly improved the solubility and dissolution rate of poorly soluble drugs, Ritonavir and Valsartan. Poloxamer 407 was used as an inert dispersing/stabilizing agent for the preparation of Nanosuspension. The other objectives of the investigation such has invivopharmacokinetic studies showed improved bioavailability of these Nanosuspension formulations when compared to microsuspensions of samedrugs. Pharmacokinetic study with Ritonavir Nanosuspension showed 150\% Cmax compared micronized drug, which may not be that much significant as far as bioavailability is concerned whereas with Valsartan the Cmax value was found to be $278 \%$ when compared to micronized drug, which can be considered as a significant improvementin bioavailability.The Nanosuspension technology proves to be a promising approach in drug delivery system to enhance the solubility of drugs belongs to BCS class II and IV and ultimately the bioavailability and can be formulated into oral dosage forms for efficient drug delivery with better patientcompliance.

\section{References}

1. Abdolhossein R.N, Altreza V, Morteza R.T (2005). Formulation of Salbutamol Sulphate microparticles using solution enhanced dispersion by supercritical carbon dioxide, Daru Journal of Pharm Sciences, 13(1):1-5.

2. Ajay J.Y, Pradeep K.G, Vadahari B.N (2012). Sustain release Nanosuspension of Acetominophen- Formulation and invitro evaluation, Int. Journal of Research in Pharm Sciences, 3(1):67-71.

3. Akhter S, Hossain I (2012). Dissolution enhancement of Capmul PG8 and Cremophor EL based Ibuprofen self emulsifying drug delivery system (SEDDS) using Response surface methodology, Int. Cur Pharm Journal, 1(6):138-150.

4. Amal S.M, Abu E.E, Gina S.E (2013). Formulation and evaluation in-situ gelling Tenoxicam liquid suppositories, Journal of life Medicine, 1(2):23-32.

5. Amidon G.L, Lennernas H, Shah V.P, Crison J.R (1995). Theoritical basis for a biopharmaceutical drug classification: the correlation of invivobioavailability, Pharm. Research,413-420.

6. Amir H.F, Peter W (2009). Nanoparticles in cellular drug delivery, Bioorganic and med. Chemistry, 17:2950-2962.

7. Amit C, Upendra N, Neha G, Sharma V.K, Khosa R.L (2012). Enhancement of solubilization and bioavailability of poorly soluble drugs by physical and chemical modifications: A recent review, Journal of Adv. Pharm Edu. and Research, 2(1):32-67.

8. Andrej D, Julijana K, Sasa B, Odon P (2009). Advantages of Celecoxib Nanosuspension formulation and transformation into tablets, Int. Journal of pharmaceutics,376:204-212.

9. Anil kumar A, Sujatha kumari M, Surekha K, Prasad CHSS, Suresh S (2012). Formulation and evaluation of sustained release Valsartan matrix tablets by using natural polymers, Int. Journal of Pharm Chemical and Biological Sciences, 2(2):146150.

10. Anilkumar J. S, Harinath N.M (2011). Design and evaluation of polylactic coglycolic acid Nanoparticles containing Simvastatin, Int. Journal of Drug Devt. and Research, 3(2): 280-289.

11. Anwar K, Rishabha M, Pramod K.S (2014). A review on bioavailability enhancement techniques of poorly soluble drugs, Int. Journal of Pharmacy, 4(3):260-266.

12. Arne W.H, John S (1979). Evaluation of sodium sterarylfumerate as tablet lubricant, Int. Journal of Pharmaceutics, 
2(3):145-153.

13. Arunkumar N, Deecaraman M, Rani C, Mohanraj K.P, Venkateshkumar K (2010). Formulation development and invitro evaluation of Nanosuspensions loaded with Atrovastatin Calcium, Asian Journal of Pharmaceutics, and 4(1):28-33.

14. Ashwini P.G, Nilesh V.K, Saptrishi D (2014). Review on enhancement of solubilization process, Am. Journal of Drug Discovery and Development, 4:134152.

15. Banavath H (2010). Nanosuspension: an attempt to enhance bioavailability of poorly soluble drugs, Int. Journal of Pharm Sciences and Research, 1(9):1-11.

16. Bankar S.G, Rhodes C.T (1998). Disperse Systems: Modern pharmaceutics. $3^{\text {rd }}$ addition

17. Battu S.K, Repca M.A, Majumdar S, Madhusudan R.Y (2007). Formulation and evaluation of rapidly disintegrating Fenoverine tablets: effects of superdisintegrants, Drug Dev. Ind. Pharmacy, 33(11):1225-1232.

18. Becon N (2000) Nanoscience and Nanotechnology shaping biomedical research, symposium report, national institues of health bioengineering consortium,http://www.becon.nih.gov/nano techsympreport.pdf.

19. Behera A.L, Patil S.V, Sahoo S. K (2010). Nanosizing of drugs: A promising approach for drug delivery, Der Pharmacia Sinica, 1(1):20-28.

20. Bentley M.V, Marchetti J.M, Ricardo N, Ali A. Z, Collett J.H (1999). Influence of lecithin on some physical, chemical properties of poloxamar gels: Rheological, microscopic and invitro permeation studies, Int. Journal of Pharmaceutics, 193(1):49-55.

21. Beril T, Andreas D, Rene D.V, Pramod R.S (2002). Bradykinin potentiation by ACE inhibitors: a matter of metabolism, $\mathrm{Br}$. Journal of Pharmacology, 137(2):276-284.

22. Bernard V.E, Mooter G.V, Patrick A (2008). Top-down production of drug Nanocrystals: Nanosuspension stabilization, miniaturization and transformation into solid products, Int. Journal of Pharmaceutics, 364:264-75.

23. Bharathi M, Sarat C.P, Lata E.R, Wasim R.S, Ravi T.A, Brito R.S, Bhaskar R.K (2012). Preparation and invitro characterization of Valsartan loaded eudragit Nanoparticles, Der Pharmacia Sinica, 3(5):516-525.

24. Bhowmik D, Chiranjib B, Jitendra Y, Chandira R.M, Sampath K.P (2010). Emerging trends of disintegrants used in formulation of solid dosage form, Der. Pharmacia Lettre, 2(1): 495-504.

25. Bindra D.S, Stein D, Pandey P, Barbour N (2014). Incompatibility of crosscarmellose sodium with alkaline excipients in a tablet formulation, Pharm. Dev. Technology, 19(3): 285-289.

26. Blagden N, Gavan P.T, York P (2007). Crystal engineering of active pharmaceutical ingredients to improve solubility and dissolution rates, $A d v$. Drug Delivery Review, 59: 617-630.

27. Bleich J, Muller B.W, Wabmus W (1993). Aerosol solvent extraction system-a new microparticle production technique, Int.. Journal of Pharmaceutics, 97(1):111-117.

28. Bo H, Thomas J.M, Christine D.K (2008). Nanowire sensors for multiplexed detection of biomolecules, Curr. Opin. Chem. Biology, 12(5):522-528.

29. Bohm B.H, Muller R.H (1999). Lab scale production unit design for Nanosuspensions of sparingly soluble cytotoxic drugs, Pharm. Sci. Techno. Today, 2:336-339.

30. Bond L, Allen S, Davies M.C, Roberts C.J, Shivji A.P, Tendler S.J, Williams P.M, Zhang, J (2002). Differential scanning calorimetry and scanning thermal microscopy analysis of pharmaceutical materials, Int. Journal of Pharmaceutics, 243:71-82

31. Bourne D.W, Banker G.S, Rhodes C.T (2002). Modern Pharmaceutics, 4th edition, New York, NY, Marcel Dekker Inc,67-92.

32. Brian W.G, Gina M.G, Lisa L. V.M, David J.G (1998). Analysis of Ritonavir in Plasma/Serum and Tissues by High- 
performance liquid chromatography, Journal of Pharm. and Toxi. methods, 40:235-239.

33. Briggs T. L, Maxwell T.J (1973). Process for preparing powder blends, US patent no 3721725.

34. Brunner E (1904).

Reaktionsgeschwindigkeit in heterogenenSystemen, Journal of Phys. Chemistry, 47:56-102.

35. Buchi N.N, Ramya K.M, Peter A.C (2012). Effect of recrystallization on the pharmaceutical properties of Valsartan for improved therapeutic efficiency, Journal of Applied Pharm. Science, 2(10):126-132. 